\title{
Techniques to Teach Communication Strategies
}

\author{
Ataollah Maleki \\ English Language Department, Faculty of Medicine, Zanjan Medical Sciences University, Zanjan, Iran \\ Email: atamaleki@hotmail.com
}

\begin{abstract}
Second language learners encounter communication problems when they attempt to use the target language. One way to overcome the problems is using effective strategies. Thus, L2 learners can benefit from teaching communication strategies to use them effectively. However, teaching and teachability of CS is a controversial issue. In this paper, it is discussed that teaching CS is useful and feasible and that techniques can be introduced to teach them. It is claimed that the Bottom-Up Approach is the framework within which such techniques can be put to use and create an atmosphere of easy communication and learning.
\end{abstract}

Index Terms - techniques, communication strategies, teachability of CS, the Bottom-up Approach, SLA

\section{INTRODUCTION}

A communication strategy is defined as an individual's attempt to find a way to fill the gap between their communication effort and immediate available linguistic resources (Maleki, 2007). Although there are other definitions of communication strategies as well, the basic idea remains the same. For example, Faerch and Kasper (1983a) define CS as "potentially conscious plans" which are used by an individual to solve a problem in order to reach a specific communication goal. It is believed that communication strategies play an important role in the development of strategic competence (e. g. Faucette, 2001); therefore, one can define communication strategies within strategic competence framework. According to Canale and Swain (1980), strategic competence is "verbal and non-verbal communication strategies that may be called into action to compensate for breakdowns in communication due to performance variables or to insufficient competence" (30). Scattergood (2003) thinks that strategic competence is cultivated if teachers create a language classroom in which communication strategies are taught and practiced.

The issue of communication strategies has been and still is an important topic in SLA. Van Lier (1988) thinks that SLA takes place through L2 learners' active participation in speech events. Rabab'ah (2005) asserts that raising consciousness of CS is crucial for a number of reasons; one being that it leads to learning by "eliciting unknown language items from the interlocutor" (194). He continues to say that "... successful language learning is not only a matter of developing grammatical, sociolinguistic, and semantic competence, but also the strategic competence which involves the use of CSs ..." (194). Also, Maleki (2007) believes that use of communication strategies is conductive to language learning and that "communication strategy training should be incorporated into school syllabuses ..." (594). Other researchers such as Tarone (1984), Bialystok (1990), Dörnyei and Thurrel (1991), Dörnyei (1995), Oxford (2001), Littlemore (2001), and many more have all praised the positive role of communication strategies in teaching and learning a second language, specifically English.

\section{TAXONOMY OF COMMUNICATION STRATEGIES}

Since the 1970s communication strategies have been the center of attention in SLA research. At that time analysis was focused on interlanguage and foreign talk, both of which involved the interactional nature of human communication (Tarone, 1977, 417). These early studies focused on identifying, defining and classifying CS into taxonomies. Later studies, however, were centered on the relationship between communication strategies and language education, especially in EFL/ESL settings.

In general, there are two approaches to the analysis and classification of communication strategies: the linguistic approach (interactional approach) and the cognitive approach. Tarone (1977, 1980, 1983) was one who for the first time suggested the linguistic approach, which was later expanded by Faerch and Kasper (1983a, 1984). According to Tarone (1977), learners' linguistic inadequacy warrants CS use by interlocutors who try to convey a meaning in question to one another. In this interactional approach, Tarone (1980) elaborates more on the definition of CS by saying "... mutual attempts of two interlocutors to agree on meaning in situations where the requisite meaning structures do not seem to be shared" (419). According to her, "...meaning structures include both linguistic and socio-linguistic structure" (Tarone, 1980, 419). On the other hand, cognitive approach to CS is placed within psycholinguistic framework. Faerch and Kasper (1983a) explain that communication strategies are processes occurring within the L2 speakers themselves with a focus on speech perception and planning and execution in speech production whenever they encounter problems (212). Thus, their description of cognitive approach is more learner-centered and communicative strategies are viewed as means for resolving problems of self-expression. However, as Mali (2007) put it "The CS execution process may start off as cognitive and result in interaction" (41). Also, Poulisse (1993) argues that one and the same strategy type can have elements of both control and analysis (171). The latter is emphasized by Kellerman and Bialystok (1997) who 
consider communication strategies as manifestations of the development of cognitive processes of analysis and control (46).

The linguistic (interactional) and the cognitive approaches to the analysis of communication strategies can be used to develop typologies for the identified CS. Tarone $(1977,1980)$ and Bialystock (1990) provide the most widely cited taxonomy of communication strategies, which are further discussed below.

\section{A typology of CS}

Tarone $(1980,429)$ summarizes types of communication strategies under five main categories, along with their subcategories. The list goes as follows:

\section{A. Paraphrase}

Paraphrase includes three subcategories which are described below.

(a) Approximation: The use of a target language vocabulary item or structure, which the learner knows is not correct, but which shares semantic features with the desired item to satisfy the speaker (e. g. "pipe" for "water pipe")

(b) Word coinage: The learner's making up a new word in order to communicate a desired concept (e. g. "airball" for "balloon")

(c) Circumlocution: The learner's describing the characteristics or elements of an object or action instead of using the appropriate TL structure (e. g. "She is, uh, smoking something. I don't know what's its name. That's, uh, Persian, and we use in Turkey, a lot of")

\section{B. Transfer}

Transfer has two elements in it.

(a) Literal translation: The learner's translating word for word from the native language (e. g. "He invites him to drink" for "They toast one another")

(b) Language switch: The learner's using the NL (native language) term without bothering to translate (e. g. "balon" for "balloon" or "tirtil" for "turtle")

\section{Appeal for Assistance}

This refers to the learner's asking for the correct term or structure (e. g. "What is this?").

\section{Mime}

Mime refers to the learner's using non-verbal strategies in place of a meaning structure (e. g. clapping one's hands to illustrate applause).

\section{E. Avoidance}

Avoidance consists of two subcategories described below.

(a) Topic avoidance: The learner's by passing concepts for which the vocabulary or other meaning structures are not known to them

(b) Message abandonment: The learner's beginning to talk about a concept but being unable to continue due to lack of meaning structure, and stopping in mid-utterance.

A series of other strategies called "achievement strategies" were proposed. They were named as so because it was believed that learners use their language resources to convey meaning, whether what they say is grammatically or socially correct. Johnstone $(1989,71$, cited in Mali, 2007, 48) lists achievement production strategies as follows:

- Code-switching and gesticulation

- Literal translation and foreignizing

- Word coinage

- Simplification

- Generalization

- Paraphrase

- Restarts and approximation

- Establish foreign identity

- Appeal for repair and confirmation

\section{TEACHING AND TEACHABILITY OF CS}

According to Mali (2007) and other researchers (see Maleki, 2007; Dörnyei and Thurrell, 1991, 1994; Tarone and Yule, 1989; Willems, 1987; Faerk and Kasper, 1986), language is best learned and taught through interaction; hence, teaching CS is the recommended fulcrum by which strategic competence can be developed. Maleki (2007) in a study considers the possibility of teaching communication strategies and the feasibility of incorporating them into school syllabi. The findings of the study reveal that teaching communication strategies is pedagogically effective, that interactional strategies are more effectively and extensively used, that communication strategies are conducive to language learning, and that language teaching materials with communication strategies are more effective than those without them (583-594). Faerk and Kasper (1986) suggest three types of activities for CS training. These are 
communication games with visual support, without visual support, and monologues (179-193). Willems (1987) recommends a number of CS instructional activities for practicing paraphrase and approximation. He insists that teachers should make learners able to achieve communication strategy ability and not seek perfection. According to him, learners' making errors is inevitable and that they can reasonably be made up for by skillfulness in the use of CS in interaction (351-364). Brooks (1992) rejects interview-type activities in favour of CS teaching through the use of jigsaw tasks, specially circumlocution and appeal for assistance (59-71). Also, Salomone and Marshal (1997) think that teaching CS can significantly improve learners' use of circumlocution. In a study, Dörnyei (1995) found that CS training might help L2 development. In the same vein, Rabab'ah (2005) believes that there are three reasons for CS training. First, CS use can lead to learning by eliciting unknown language items from the interlocutor, specially appeal for assistance. Second, it is the means by which conversation continues. Third, CS use helps learners solve their communication problems and achieve their communicative goals (194).

Despite the fact that many SLA researchers lend support to CS training, some opposition to it has been expressed. Bialystok (1990) and Kellerman (1991) argue that one should teach the language itself rather than the strategies. Schmidt (1983) believes that L2 learners develop their strategic competence at the expense of their linguistic competence. According to Skehan (1998), using CS by skilled learners may hinder the development of their interlanguage knowledge resources. Others such as Ellis and Barkhuizen (2005) argue that CS teaching does not contribute to the development of linguistic competence, and that the role of communication strategy in SLA is considerably vague (172). Finally, Oxford (2001) asserts, "positive results about strategy instruction are pleasing; however, we might not have the complete picture because educational studies reporting ineffective treatments are rarely published"(170).

\section{THE BOTTOM-UP APPROACH}

The Bottom-Up Approach is a new approach to teaching English as a foreign language (see Maleki, 2005) in which the traditional ad hoc top-to-bottom listening-speaking-reading-writing order of teaching has been reversed. As techniques for teaching CS introduced in the current paper is based on this new approach, it is necessary to review it briefly.

The Bottom-Up Approach is based on motivation theory second language learning. Dörnyei (2001) notes that teaching effectiveness depends on teacher skills in motivating learners. Experience has proved that fear of speaking in public in a foreign language and lack of privacy eliminates motivation of language learning (116). Unlike other methods, the Bottom-Up Approach attempts to develop, maintain, and increase the motivation needed in language classrooms (Maleki, 2005, 5).

The Bottom-Up Approach gives prominence to writing; however, it views language as a total entity. As Maleki (2005) states, writing provides privacy and self-negotiation for learners, and becomes a channel through which learners overcome their fear and anxiety, achieve some degree of autonomy, and kill causes of demotivation (7). The actual method starts with the teacher specifying a type. A type includes the things that surround learners from without and within, from every day life chores to emotional changes, merry-making and qualms. For the type to be specifically targeted, learners need certain specialized and general vocabulary. It is the job of the teacher to supply the necessary words. The words are presented in written form on the blackboard or an overhead projector may be used. Then, they ask learners to have a pen and paper handy. Learners should write either the answers to certain questions, or should follow orders in writing. Once all the questions and answers are complete, and all the orders are followed and done in writing, the teacher calls on learners to sit back and think for a while. The purpose is to allow learners to negotiate with the self and arrange the answers and orders in the form of a well-organized and well-thought passage. Next, come checks and balances. The teacher asks learners to exchange their compositions with their neighbours. Again, the teacher calls for learners' silence. They sit back and check out their neighbour's work very carefully. Once finished with the latter, they ask students to read their neighbours' compositions loudly. While they read, the teacher corrects them for their pronunciation, grammar, vocabulary, and style errors. Immediately after smoke is cleared, learners should present their own compositions orally with other students listening attentively. At this stage, students are asked to take notes. From the notes taken from a read composition of their own choice, they may form questions, and the student in point may answer them (Maleki, 2005, 8).

\section{TECHNIQUES FOR TEACHING CS}

Techniques introduced here will be used to teach paraphrase, transfer, appeal for assistance, and mime. The Bottom-Up Approach is the framework within which the techniques are put to use.

\section{A. Paraphrase}

1. The teacher follows procedures below to teach approximation strategy:

(a) Divide the class into teams of four or five students

(b) Ask students to have pen and paper handy

(c) List target language vocabulary on the blackboard which share semantic features with the main items to be taught 
during the session

(d) Write examples of vocabulary items identified with their approximations

(e) Ask students to identify main items according to their approximations listed on the blackboard

(f) Ask members of each team to compare their identified items with those of other team members and to resolve their differences on discussion

(g) Ask a member of each team to read out the identified items agreed upon within the team

(h) Have the class discuss, compare, and prepare the final list of the main items

(i) write the final list on the blackboard for all class to see

(j) Have each team write two sentences one with the main item and the other with its approximation

(k) Have teams read their written sentences and correct them

Commentary

The technique introduced to teach approximation strategy helps learners to find replacement for the vocabulary they either don't know or they have them in their passive reserve but are not able to retrieve them. This, in turn, will help students learn to hold their ground and do not stop the conversation. Engaged in approximation strategy practice within the Bottom-Up Approach, learners feel free to negotiate with the self and negotiate meaning with the team-mates and others by taking their time and eliminating their fear and anxiety, two major obstacles to foreign language learning.

2. The teacher follows procedures below to teach word coinage strategy:

(a) Ask the class to sit back and watch you drawing on the blackboard with pen and paper ready

(b) Draw sketches of ten objects on the blackboard, e. g. a safety pin, a straight pin, a clothes pin, a bobby pin, a needle, a paper clip, etc.

(c) Ask students to write names of the objects drawn on the blackboard

(d) Allow them time to think

(e) Have learners exchange papers

(f) Allow them to correct each other's definitions

(g) Have them discuss the corrected definitions in pairs

(h) Get each of them read out their definitions with others listening attentively

(i) Choose definitions closest in meaning to the main names

(j) Have students write the definitions for later use

(k) Dub the practice word coinage for the students to learn how they can overcome problems with object names

Commentary

Most language learners have problems with communicating new concepts. Word coinage is an important strategy to bypass the barriers they face. The proposed technique is very effective in forcing the learners to think and invent definitions for the objects or concepts for which they have no name or word in long memory. The Bottom-Up Approach putting emphasis on writing removes learners' stress and anxiety and provides them with enough time to think and invent new structures. It seems Dörnyei (2001) is right in saying that teachers should help learners maintain and increase self-confidence by fostering the belief that competence is a changeable aspect of SLA development and that favourable self-conception of L2 competence can be promoted by providing regular experiences of success. That a learner is able to give names to objects and concepts is a great success in developing their strategic competence.

3. The teacher follows procedures below to teach circumlocution strategy:

(a) Ask the class to think of a number of objects and concepts whose names and definitions are unknown to them

(b) Ask students to write the names and definitions of the objects and concepts in their native language

(c) Have the students describe in writing the characteristics or elements of the objects and concepts in English

(d) Give them enough time to perform stage (c)

(e) Ask them to read their descriptions loudly while others listening

(f) Ask them to identify the objects or concepts in their native language

(g) Write the names or definitions of the objects or concepts in English on the blackboard

(h) Ask students to write the objects or concepts in English in their notebooks with original descriptions opposite to them

(i) Repeat the process for each student

Commentary

Teaching circumlocution strategy within the Bottom-Up Approach has many benefits. First, students learn to describe objects and concepts. Second, they practice writing in English. Third, they learn new words and structures during circumlocution drill. Fourth, they learn to keep their ground in communication even if they face objects or concepts for which they have no known names or definitions.

\section{B. Transfer}

1. The teacher follows procedures below to teach literal translation strategy:

(a) Divide the class into teams of 5

(b) Write 5 idiomatic expressions or expressions little known to the students in the form of sentences on the blackboard

(c) Give the meanings of the expressions in the students' native language or explain them in a way that they can 
understand their meaning

(d) Ask the teams to translate the sentences on the blackboard literally according to your explanation

(e) Give them enough time to write their translations

(f) Ask a member of each team to read out their translated sentences

(g) Listen and correct them orally

(h) Choose the best of the translated sentences and write them on the blackboard

(i) Ask the students to take notes of them and use them in communication whenever needed

(j) Repeat the process using five new expressions

Commentary

Transfer strategy is inevitable in the course of second language learning. If used wrongly, the transferred items might get fossilized. Such fossilized structures will be hard to eliminate later. Therefore, teaching students to use transfer strategy in communication is of utmost importance.

2. The teacher follows procedures below to teach language switch strategy:

(a) Collect as many borrowed words as you can from the target language found in the students' native tongue

(b) Determine the phonological changes in the words

(c) Transcribe the words according to the phonological changes in the students' native language

(d) List the words in three columns: target language phonology, native language phonology, transcriptions of native language phonological forms

(e) Make copies of the list and distribute them among the students

(f) Practice pronunciation and the meaning content of the words, as some words may even have changed their meanings in the native language

(g) Ask students to be on their guard in using such words in communication

Commentary

Language switch is, in fact, a negative transfer which may hinder rather than facilitate language learning; therefore, it must be pre-empted. The technique introduced can help language switch problem to solve.

\section{Appeal for Assistance}

The teacher follows procedures below to teach appeal for assistance strategy:

(a) Divide the class into four or five teams

(b) Use identifying games for each team to practice questions like "What's this/that?; What are these/those?; Who's this/that?; How do you say ... in English?; etc."

(c) Have the students in each team hold up or touch or point to objects or other students to ask the questions

(d) Get students in other teams answer the questions in writing

(e) Ask representatives of each team read out their answers

(f) Have those who answer correctly ask a similar question in return

(g) Use other types of games such as guessing games, unfinished drawings, and wrapped objects to reinforce appeal for assistance strategy

Commentary

Appeal for assistance is probably the most common communication strategy used by learners and found in textbooks (see Maleki 2007; Faucette, 2001). Faucette (2001) thinks that appeal for assistance strategy is useful for lower-proficiency second language learners which allows them to immediately participate in conversation. The technique introduced here will help speakers hold the floor and find correct answers for the questions they face.

\section{Mime}

The teacher follows procedures below to teach mime strategy:

(a) Divide the class into teams of four

(b) Give each team a list of scrambled words

(c) Give them time to rearrange each scrambled word into at least one correct word

(d) Ask members of each team to mime each rearranged word while members of other teams guess the word

(e) Ask the latter to write the guessed words

(f) Have them read out their guessed words

(g) Get them compare the words with the original mime and correct them

(h) Repeat the round with other rearranged words

Commentary

It is true that mime is universal. If learners learn to mime when they come to crossroads, they will be able to continue the conversation and will not be deterred by fear of paucity of linguistic competence. The latter is a major demotivating factor which sometimes terminates plans to learn a second or a foreign language.

\section{E. Avoidance}

Avoidance strategy is defined as an alternative to giving up. Therefore, it is not recommended as a useful strategy which will lead to learning (Faerch and Kasper, 1983a). Language teachers must be on their guard and be ready to help 
learners whenever they feel students try to avoid or abandon a topic or a massage. Avoidance is due to poor linguistic competence or weak strategic competence. If allowed to take root, avoidance strategy will kill innovative thinking of the learner. Teaching within the Bottom-Up Approach is a way to help learners avoid avoidance strategy and learn to come to terms with second language learning problems.

\section{CONCLUSION}

Teaching communication strategies is controversial in two ways: whether to teach them or not; if yes, how? In what was discussed in the previous sections, it was argued that teaching CS is not only useful, but also feasible. As communication strategies are conducive to language learning, techniques were introduced to teach them. Most of the techniques presented here are pinned down on the Bottom-Up Approach, which is a new approach to teaching English as a foreign/second language.

\section{REFERENCES}

[1] Bialystok, E. (1990). Communication Strategies. Blackwell, Oxford.

[2] Brooks, F. (1992). Can we talk? Foreign Language Annals 25 (1), 59-71.

[3] Canale, M. \& M. Swain. (1980). Theoretical bases of communicative approaches to second language teaching and testing. Applied Linguistics 1(1), 1-47.

[4] Dörnyei, Z. \& S. Thurrell. (1991). Strategic competence and how to teach it. ELT Journal 45(1), 16-23.

[5] Dörnyei, Z. \& S. Thurrell. (1994). Teaching controversial skills intensively: Course content and rationale. ELT Journal 48(1), 40-49.

[6] Dörnyei, Z. (1995). On the teachability of communication strategies. TESOL Quarterly 29(1), 55-85.

[7] Dörnyei, Z. (2001). Teaching and Researching Motivation. London: Pearson Education Limited.

[8] Ellis, R. \& G. Barkhuizen. (2005). Analysing Learner Language. Oxford: Oxford University Press.

[9] Faerch, C. \& G. Kasper. (1983a). Plans and strategies in foreign language communication. In C. Faerch \& G. Kasper (Eds.), Strategies in Interlanguage Communication. London: Longman, 20-60.

[10] Faerch, C. \& G. Kasper. (1984). Two ways of defining communication strategies. Language Learning 34 (1), 45-47.

[11] Faerch, C. \& G. Kasper. (1986). Strategic competence in foreign language teaching. In G. Kasper (Ed.), Learning, Teaching and Communication in the Foreign Language Classroom. Aarhus: Aarhus University Press, 179-193.

[12] Faucette, P. (2001). A pedagogical perspective on communication strategies: Benefits of training and an analysis of English language teaching materials. Second Language Studies 19(2), 1-40.

[13] Johnstone, R. (1989). Communicative Interaction. London: CILT.

[14] Kellerman, E. (1991). Compensatory strategies in second language research: A critique, a revision, and some implications for the classroom. In R. Phillipson, E. Kellerman, L. Selinker, M. Sharwood Smith \& M. Swain (Eds.), Foreign/second Language Pedagogy Research. Multilingual Matters. UK: Clevedon, 142-161.

[15] Kellerman, E. \& E. Bialystok. (1997). On psychological plausibility in the study of communication strategies. In G. Kasper \& E. Kellerman (Eds.), Communication strategies. London: Longman, 31-48.

[16] Littlemore, J. (2001). An empirical study of the relationship between cognitive style and the use of communication strategy. Applied Linguistics 22 (2), 241-265.

[17] Maleki, A. (2005). A New Approach to teaching English as a Foreign Language: The Bottom-Up Approach. http://www.asian-efl-journal. com/pta-april-05-am.php.

[18] Maleki, A. (2007). Teachability of communication strategies: An Iranian experience. System 35 (4), 583-594.

[19] Mali, Z. O. (2007). Exploring communication strategy use by learners of Isizulu in Synchronous computer-mediated communication (S-CMC). Unpublished Ph. D dissertation, Iowa University, USA.

[20] Oxford, R. L. (2001). Language Learning Strategies. In R. Carter \& D. Nunan (Eds.), Teaching English to Speakers of Other Languages. Cambridge: Cambridge University Press, 166-172.

[21] Poulisse, N. (1990). The Use Compensatory Strategies by Dutch Learners of English. Sneldruk, Enschede.

[22] Rabab'ah, G. (2005). Communication problems facing Arab learners of English. Journal of Language and Learning 3 (1), 194.

[23] Salomone, A. \& F. Marshal (1997). How to avoid language breakdown? Circumlocution! Foreign Language Annals 30 (4), 473-482.

[24] Scattergood, E. (2003). Encouraging the Use of Strategies to Improve Communication in the EFL Classroom. The Language Teacher, http://www.jalt-publications. org/tlt/articles/2003/06/scattergood.

[25] Schmidt, R. (1983). Interaction, acculturation and the acquisition of communication competence. In N. Wolfson \& E. Judd (Eds.), Sociolinguistics and Second Language Acquisition. Rowley: Newbury House, 137-174.

[26] Skehan, P. (1998). A Cognitive Approach to Language Learning. Oxford: Oxford University Press.

[27] Tarone, E. (1977). Conscious communication strategies in interlanguage: A progress report. In H. D. Brown, C. A. Yorio, \& R. H. Crimes (Eds.), On TESOL 77: Teaching and learning ESL. Washington: TESOL.

[28] Tarone, E. (1980). Communication strategies, foreigner talk, and repair in interlanguage. Language Learning 30 (2), 417-431.

[29] Tarone, E. (1983). Some thoughts on the notion of communication strategy. In C. Faerch \& G. Kasper (Eds.), Strategies in interlanguage communication. London: Longman, 61-74.

[30] Tarone, E. (1984). Teaching strategic competence in the foreign language classroom. In S. Savingnon \& M. Berns (Eds.), Initiatives in Communicative Language Teaching. Reading: Addison Wesley, 127-136.

[31] Tarone, E. \& G. Yule (1989). Focus on the Language Learner. Oxford: Oxford University Press.

[32] Van Lier, L. (1988). The classroom and the language learner. London: Longman.

[33] Willems, G. (1987). Communication strategies and their significance in foreign language teaching. System 15 (3), $351-364$. 


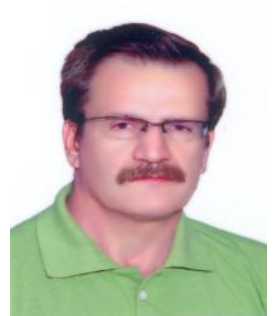

Ataollah Maleki is currently Associate Professor of TEFL at Zanjan Medical University, IRAN. His main interest of research is communication strategies, EFL teaching, teaching and testing, ESP, discourse analysis, and phonetics. He has been engaged in teaching English and applied linguistics for more than twenty years. He holds a Ph. D degree in TEFL, an MA in TEFL, and a postgraduate diploma in applied linguistics and phonetics. He has published a number of books and articles in his areas of interest in academic journals. 